\title{
The study of psychometric test for detection and assessment in subclinical hepatic encephalopathy
}

\author{
Kanwar G. ${ }^{1}$. Singh S. ${ }^{2}$, Pandey S. ${ }^{3}$, Paikra S. ${ }^{4}$ \\ ${ }^{1}$ Dr. Gopal Kanwar, Associate Professor, Department of Medicine, GMC, Ambikapur, CG, ${ }^{2}$ Dr. Sanjay Singh Assistant \\ Professor, Department of Medicine, GMC, Ambikapur, CG, ${ }^{3}$ Dr. Sachin Pandey, Assistant Professor, Department of \\ Community Medicine, CIMS, Bilaspur, CG, ${ }^{4}$ Dr. Shashi Paikra, Demonstrator, Department of Anatomy, CIMS, Bilaspur, \\ CG, India.
}

Corresponding Author: Dr Sanjay Singh, Assistant Professor, Department of Medicine, GMC, Ambikapur, CG. Email: drsanjayganga@gmail.com

\begin{abstract}
Background: During past two decades, psychometric tests have been used extensively for detection of SHE. However, the results have been variables with different tests. In real practice we require the tests, which can be administered quickly by treating physician with simplicity and with simple instrument or only with a simple form. Objective: (1) To apply a battery of psychometric tests in cases of cirrhosis of liver. (2) To correlate findings of psychometric tests with Child`s index of severity for cirrhosis of liver. Methodology: 25 patients of cirrhosis of liver diagnosed by ultrasonography, biochemical and clinical evidence, admitted in the Medicine ward, will constitute the study group. These patients will undergo a battery of psychometric tests and EEG along with other routine hematological and radiological test. 25 control group with confounding factors as age, sex, education and socioeconomic status. Results: We observed that on WAPIS test cirrhotic performed significantly worse than controls. Mean IQ \pm SD non-Alcoholic cirrhotic on WAPIS was [67.78 \pm 11.29$]$ and Mean IQ \pm SD of alcoholic cirrhotics was (66.45 \pm 9.71$)$. On analysis of data the difference was not significant $(\mathrm{p}>0.005)$. Taken together the performance test was abnormal in $14(56 \%)$ cases. Conclusion: We concluded that for quick assessment of mental status and screening for detecting SHE in cases of cirrhosis of liver with portal hypertension, TMT test is useful and for complete assessment of cerebral function derangement WAPIS is most sensitive and complete test.
\end{abstract}

Key words: Subclinical Hepatic Encephalopathy, Outdoor Patients, Trail Making Test

\section{Introduction}

The major complication of chronic liver disease with development of portosystemic collaterals is portosystemic encephalopathy (PSE). It has been seen that spectrum of hepatic encephalopathy incorporate not only the traditional clinical stage 1 to 4 but also subclinical latent stages. It has become apparent that there is subtle stage of hepatic encephalopathy that falls between two of the traditional grades viz. between normal mental stage grade $\mathrm{O}$ and grade $\mathrm{I}$. In this stage patients do not have any overt clinical signs. In this stage patient is in compensatory hepatic encephalopathy. This stage is termed as latent or subclinical hepatic encephalopathy (SHE). Latent or subclinical hepatic encephalopathy is a disorder in

Manuscript received: $10^{\text {th }}$ May 2018

Reviewed: $20^{\text {th }}$ May 2018

Author Corrected: $25^{\text {th }}$ May 2018

Accepted for Publication: $29^{\text {th }}$ May 2018 patients with chronic liver disease, usually in whom there is presence of one or two demonstrable or quantifiable neuropsychological or neurophysiological abnormalities, this clinically latent impairment may be even more important for the patient's daily health than episodes of overt PSE because between overt episodes he has to face the tasks of daily life where as during episodes of PSE he is generally taken care of in a hospital. For making the diagnosis of latent hepatic encephalopathy, biochemical and psychometric tests are required. It is probable that EEG abnormalities will also be present as a reliable marker of this syndrome. The SHE detection does require sophisticated instrumentation like EEG and visual evoked potentials. Costly biochemical tests require specifically trained person for detection but SHE can also be detected by using simple and inexpensive psychometric tests. 


\section{Original Research Article}

Objective: Our aim was to establish the presence of SHE amongst ambulatory care patients with cirrhosis of liver with portal hypertension by evaluating the percentage of cases with abnormal Psychometric tests.

(1) To apply a battery of psychometric tests in cases of cirrhosis of liver.

(2) To correlate findings of psychometric tests with Child's index of severity for cirrhosis of liver.

\section{Material and Methods}

Place of Study: This study was done in the Department of Medicine GMC, Ambikapur.

Type of Study: This study is type of prospective study as taken 25 patients of cirrhosis of liver, diagnosed by Ultrasonography, biochemical and clinical evidence attending the medicine OPD or admitted in the medicine ward will constitute the study group.

Sampling Method: We have taken randomly 25 cirrhosis patients who have fitted according to inclusion criteria from admitted or attended in OPD of Medicine Department.

Sample Collection: For the purpose of study 25 patients were studied having cirrhosis of liver. These patients will undergo a battery of psychometric tests along with other routine hematological and radiological investigation. 25 healthy individuals matched for age, sex, education and socioeconomic status will be taken as controls.

Evaluation was done in each case on a semi-structured proforma and on the following rating instruments which are mentioned in materials.

\section{Inclusion Criteria}

Hospitalized male and female patients, who have satisfied all of the following conditions, were included in the study.

1. All patients of cirrhosis of liver (verified by clear cut clinical evidence of portal hypertension, USG and biochemical analysis) without any clinical evidence of encephalopathy.

2. Absence of any clinically detectable cerebral dysfunction.

3. No history of alcohol intake for last six months.

4. No patient underwent a previous shunt or decompressive surgery.
5. No previous history of hepatic encephalopathy, neurological or psychiatric disorder.

\section{Exclusion Criteria}

1. Hepatic encephalopathy stages greater than grade $\mathrm{O}$.

2. Patient or person taking drugs that can affect function of brain.

3. Patient or person having disease, which affects functions of brain like patient with renal insufficiency.

4. Patient having history of drug abuse or alcohol intake during last 6 month.

5. Liver status complicating the interpretation of the tests like hepatic renal syndrome.

Materials: In present study we have used battery of inexpensive, fast and simple psychometric tests which include:

i. Wechsler Adult performance intelligence scale [1]

- Picture completion test

- Digit Symbol test

- Block design test

- Picture arrangement test

- Object assembly test

ii. Trail making test[2]

- Number connection test $\mathrm{A}_{1}$

- Number connection test $\mathrm{A}_{2}$

- Number connection test $\mathrm{B}_{1}$

- Number connection test B2

These tests can be administered by psychologists, internists, nurses, technicians, and even by receptionists These tests could be used on outdoor patients.

By using these simple and quick tests patients of SHE can be detected, who are in occupation that require skill and concentration.

Statistical Methods: We have analyzed data by using SPSS 21.0 Version. We have drawn inferences as Mean, SD of cases and controls group of respective variables.

We have found the difference between two cases and control by $t$ test with significant $p$ value. 


\section{Results}

In the present study in which $92 \%$ of cases and control were male and $8 \%$ female. $12 \%$ of cases belongs to $20-29$ years group. $12 \%$ cases to $30-39$ years age group, $40 \%$ case to $40-49$ yrs age group, $28 \%$ to $50-59$ yrs age group, $8 \%$ cases to 60 -above yrs age group. Age wise distribution of controls in present study shows $8 \%$ controls belongs to $20-29$ yrs age group, $16 \%$ to $30-39$ yrs age group, $36 \%$ to $40-49$ yrs age group, $32 \%$ to $50-59$ yrs age group and $8 \%$ to 60 -above age group. $64 \%$ case were illiterate, $12 \%$ case had education up to middle school. $12 \%$ cases had education up to higher secondary and $4 \%$ cases were graduate. In control $68 \%$ of controls were illiterate, $12 \%$ had education up to middle school, $20 \%$ had education up to Higher Secondary and $0 \%$ of controls graduate. The $80 \%$ of cases belongs to low socioeconomic status and $20 \%$ belongs to middle socioeconomic status for control group $72 \%$ control belong to low socioeconomic status and $28 \%$ belongs to middle socioeconomic status. We observed that on WAPIS test cirrhotic performed significantly worse than controls. Mean IQ \pm SD non Alcoholic cirrhotic on WAPIS was [67.78 \pm 11.29 ] and Mean IQ \pm SD of alcoholic cirrhotics was $(66.45 \pm 9.71)$. On analysis of data the difference was not significant $(\mathrm{p}>0.005)$. Taken together the performance test was abnormal in $14(56 \%)$ cases.

Table-1: Number connection test in cases and percentage of cases with abnormal test in cirrhotic patient.

\begin{tabular}{|c|c|c|c|c|c|c|c|c|}
\hline No. & Name & No. & Mean & $\begin{array}{l}\text { STD } \\
\text { DEV }\end{array}$ & MIN. & MAX & $\begin{array}{c}\text { Abnormal } \\
\text { No. }\end{array}$ & $\begin{array}{c}\text { Abnormal } \\
\%\end{array}$ \\
\hline 1 & $\begin{array}{l}\mathrm{A}_{1} \\
\text { test }\end{array}$ & 25 & 53.40 & 17.07 & 30 & 90 & 14 & $56 \%$ \\
\hline 2 & $\begin{array}{l}\mathrm{A}_{2} \\
\text { test }\end{array}$ & 25 & 48.36 & 16.33 & 25 & 82 & 14 & $56 \%$ \\
\hline 3 & $\begin{array}{c}\mathrm{B}_{1} \\
\text { test }\end{array}$ & 25 & 54.40 & 18.85 & 24 & 112 & 16 & $64 \%$ \\
\hline 4 & $\begin{array}{c}\mathrm{B}_{2} \\
\text { test }\end{array}$ & 25 & 51.96 & 18.69 & 30 & 109 & 15 & $60 \%$ \\
\hline
\end{tabular}

Above table shows that out 25 cases test score time that range from 30 to $90 \mathrm{sec}$ for $\mathrm{A}_{1}$ test, 25 to $82 \mathrm{Sec}$ for $\mathrm{A}_{2}$ test, 24 to $112 \mathrm{Sec}$ for $\mathrm{B}_{1}$ test 90 to $109 \mathrm{Sec}$ for $\mathrm{B}_{2}$ test.

In cirrhotic Mean corrected test score time was $53.40 \pm$ S.E. 3.414 for $\mathrm{A}_{1}$ test, $48.36 \pm \mathrm{SE} 3.266$ for $\mathrm{A}_{2}$ test, $54.40 \pm \mathrm{SE}$ 3.77 for $\mathrm{B}_{1}$ test and $51.96 \pm 3.738$ for $\mathrm{B}_{2}$ test. This value statistically differed $(\mathrm{p}<2.001)$ when compared to control. The prevalence of neuropsychological abnormalities in cirrhotic subjects judged as having a normal mental state on clinical assessment was $56 \%$ for $A_{1} 56 \%$ for $A_{2} 64 \%$ for $B_{1}$ and $60 \%$ for $B_{2}$ test, exceeding the normal range of psychometric test.

Table 2: Performance of cases and control in 5 sub tests of WAPIS

\begin{tabular}{|c|c|c|c|}
\hline Test & $\begin{array}{c}\text { Case } \\
(\text { Mean } \pm \text { SD })\end{array}$ & $\begin{array}{c}\text { Control } \\
(\text { Mean } \pm \mathrm{SD})\end{array}$ & Significance \\
\hline $\begin{array}{c}\text { Picture } \\
\text { complication }\end{array}$ & $6.44 \pm 2.66$ & $11.50 \pm 2.97$ & $\begin{array}{c}\mathrm{t}=3.363 \\
\mathrm{df}=48 \\
\mathrm{P}<0.0001\end{array}$ \\
\hline Digit Symbol test & $2.72 \pm 1.10$ & $12.28 \pm 2.26$ & $\begin{array}{c}\mathrm{t}=18.989 \\
\mathrm{df}=48 \\
\mathrm{P}<0.00001\end{array}$ \\
\hline Block design test & $4.36 \pm 2.08$ & $9.84 \pm 2.59$ & $\begin{array}{c}\mathrm{t}=8.244 \\
\mathrm{df}=48 \\
\mathrm{P}>0.0001\end{array}$ \\
\hline $\begin{array}{c}\text { Picture } \\
\text { arrangement }\end{array}$ & $6.60 \pm .2 .93$ & $7.96 \pm 3.03$ & $\begin{array}{c}\mathrm{t}=1.612 \\
\mathrm{df}=48 \\
\mathrm{P}>0.05\end{array}$ \\
\hline $\begin{array}{c}\text { Object } \\
\text { Assembly }\end{array}$ & $3.84 \pm 2.30$ & $5.48 \pm 3.62$ & $\begin{array}{c}\mathrm{T}=1.912 \\
\mathrm{df}=48 \\
\mathrm{P}>0.05\end{array}$ \\
\hline
\end{tabular}




\section{Original Research Article}

Above table shows the performance of cases and control in five subsets of WAPIS Mean scaled score of control in picture completion test was $(11.5 \pm 2.97)$. In digit symbol test $(12.28 \pm 2.26)$ in block design test $(9.87 \pm 2.59)$ in picture arrangement $(7.96 \pm 3.03)$ and in object assembly $(5.48 \pm 3.62)$ while mean scale scores of cases for PCT was $(6.44 \pm$ 2.66) Digit symbol test $(2.72 \pm 1.10)$, Block design test $(4.36 \pm 2.08)$ picture arrangement $(6.60 \pm 2.93)$ and for object assembly (3.84 \pm 2.30$)$.

On statistical analysis of data there is significant difference between performances of cases and control in Digit Symbol test $(p>0.00001)$ and picture completion and block design test $(p<0.00001)$ while for picture arrangement and object assembly the difference is not statistically significant $(\mathrm{p}>0.05)$.

Table-3: Connection of alcoholic and non-alcoholic CIRROTIC patients on WAIPS test.

\begin{tabular}{|c|c|c|}
\hline & Non alcoholic & Alcoholic \\
\hline Mean IQ & $67.78 \pm 11.29$ & $66.45 \pm 9.71$ \\
\hline Significance & $\mathbf{t}=\mathbf{0 . 3 1 1 d f}=23$ & $\mathbf{P}>\mathbf{0 . 0 5}$ \\
\hline
\end{tabular}

Above table shows comparison of mean IQ of cases on performing WAPIS test the mean IQ of nonalcoholic cirrhotics were $67.78 \pm 11.29$ and mean IQ of alcoholic cirrhotics were $66.45 \pm 9.71$. On statistical analysis of data the difference was not significant $(\mathrm{p}>0.05)$.

Table-4: Performance between alcoholic and non- alcoholic patients on Trail making test.

\begin{tabular}{|c|c|c|c|}
\hline & Non-alcoholic & Alcoholic & Significance \\
\hline Mean Score SD & $58.78 \pm 16.83$ & $51.64 \pm 18.03$ & $\mathrm{t}=0.45$ \\
$\mathrm{df}=23$ \\
$\mathrm{P} 1$ test
\end{tabular}

Above table shows mean test time taken by cases in performing TMT. Mean time taken by nonalcoholic cirrhotic was $58.78 \pm 16.83$ for $\mathrm{A}_{1}$ test $48.50 \pm 15.66$ for $\mathrm{A}_{2}$ test, $56.14 \pm 20.49$ for $\mathrm{B}_{1}$ test and $54.00 \pm 21$ for $\mathrm{B}_{2}$ test. Mean time taken by alcoholic cirrhotic was $51.64 \pm 18.03$ for $A_{1}$ test $48.18 \pm 17.19$ for $A_{2}$ test, $52.18 \pm 17.24$ for $B_{1}$ test and $49.30 \pm 15.71$ for $B_{2}$ test. On statistical analysis of data the difference was not significant $(\mathrm{p}>0.05)$.

Table-5: Distribution of cases on performing "WAPIS test" according to intelligence classification.

\begin{tabular}{|c|c|c|c|c|c|c|c|c|}
\hline IQ Range & Classification & $\mathbf{2 0 - 2 9}$ & $\mathbf{3 0 - 3 9}$ & $\mathbf{4 0 - 4 9}$ & $\mathbf{5 0 - 5 9}$ & $\mathbf{6 0 - a b o v e}$ & Total & \% \\
\hline $130-$ above & Very superior & 0 & 0 & 0 & 0 & 0 & 0 & $0 \%$ \\
\hline $12-129$ & Superior & 0 & 0 & 0 & 0 & 0 & 0 & $0 \%$ \\
\hline $110-119$ & Bright normal & 0 & 0 & 0 & 2 & 0 & 0 & $0 \%$ \\
\hline $90-109$ & Average & 0 & 0 & 0 & 3 & 2 & 0 & $0 \%$ \\
\hline $80-89$ & Dull normal & 1 & 0 & 1 & 1 & 0 & 3 & $12 \%$ \\
\hline $70-79$ & Borderline & 1 & 1 & 3 & 2 & 1 & 8 & $32 \%$ \\
\hline 69 and below & Mental defective & 1 & 2 & 6 & 4 & 1 & 14 & $56 \%$ \\
\hline
\end{tabular}

Above table shows that on 'WAPIS TEST' out of 25 Subjects, $8 \%$ of the performed of $12 \%$ cases was in the I.Q. Range Dull normal, $32 \%$ in range of Borderline and $56 \%$ in cases performance the range of mental defectives. 


\section{Discussion}

The first recognition of SHE was reported in 1970 [1]. The investigations were programmed for variety of purposes. In several the primary goal of study was to determine the frequency of SHE after portal systemic decompressive surgery. In several others, investigation was performed to evaluate specific psychometric test such as Trail making test, or by electroencephalographic procedures such as sensory evoked potentials in detecting SHE.

Since 1970 several groups have been attempting to grade portal systemic encephalopathy using several modifications of trail making test $\&$ a psychometric test that has been used to evaluate organic brain damage for more than 40 years [2,3,4]. In principle this type of test has existed in various forms and under various names for almost 40 years. Although a series of studies have shown this test to be a valid index of organic brain damage, organic and non-organic disorders cannot clearly be differentiated $[5,6]$.

This test has been used primarily as one of a battery of tests administered on a single occasion to assess and individual's general aptitude. It`s a simple, reliable, semi quantitative method for assessment of mental status in patients with hepatic encephalopathy. In our study we had used four variable of trail making test $A_{1}$, $A_{2}, B_{1}, B_{2}$ out of 25 control subjects exhibited test score times that range from 21 to 46 second (Mean 31.76 7.72) for $A_{1}$ test 20 to $42 \mathrm{sec}$ (mean 29.08 \pm 6.59) for $A_{2}$ test 25 to $46 \mathrm{sec}$ (mean $34.44 \pm 7.15$ ) for $\mathrm{B}_{1}$ test and from 20 to $42 \mathrm{sec}$ (mean $31.76 \pm 7.13$ ) for $\mathrm{B}_{2}$ test. Normal range, $90 \%$ of confidence limit was assessed a below 47.50 for $A_{1}$ test, 42.26 for $A_{2}$ test, 48.74 for $A_{1}$ test, 46.02 for $\mathrm{B}_{2}$ test.

In cirrhotics the mean corrected test score time was $53.40 \pm$ SE $3.414 \mathrm{sec}$ for $\mathrm{A}_{1}$ Test $48.36 \pm \mathrm{SE} 3.266$ for $\mathrm{A}_{2}$ test $54.40 \pm$ SE 3.77 for $B_{1}$ test and $51.96 \pm 3.738 \mathrm{sec}$ for $\mathrm{B}_{2}$ test. This value statistically differed $(\mathrm{p}>0.0001)$ when compared to controls. The prevalence of neuropsychological abnormalities in cirrhotic subjects judged as having a normal mental state on clinical assessment was $56 \%$ (14 out of 25) for $\mathrm{A}_{1}$ and $\mathrm{A}_{2}$ test and $64 \%$ (16 out of 25 ) for $B_{1}$ test and $60 \%$ (15 out of $25)$ for $B_{2}$ test, exceeding the normal range of psychometric test.

In the individual studies using TMT, abnormalities indicative of SHE were found 33 to $100 \%$ of the patient's tested. 18 Cirrhotics (33\%) out of 54 showed impaired performance on using TMT [7]. Cerebral function were studies in 20 non alcoholic cirrhotics, number connection Test was abnormal in $13(63 \%)$ patients [8]. They found impaired performance on trail $\mathrm{B}$ in $60 \%$ and on trail $\mathrm{A}$ in $53 \%$ cases [9].

4 out of 17 patients taken time exceeding normal range for completing NCT [10]. We have not considered the age factor. Author used the VEP to delineate a state of SHE and compared it with NCT, they concluded when the NCT between the groups was compared according the 3 age groups there was no significant difference between the patients and control from the 37 to 67 year of age group [11]. There was significant prolongation in the patients compared to the control in the 16-36 years age group. However not all have considered the age factor. In study of the age difference in the group was significant [12]. Although other Authors found no correlation of performance with age [13][14][15].

They did not correlate the age with TMT, even though there was no significant difference in age between the groups [1]. In our study as we have taken control of same age so we did not apply age norm. Authors were found significant correlation between the severity of liver disease and most test of performance in cirrhotic group [16]. The WAPIS performance test is general measure of nonverbal skills. Significant difference was found in performance between cases and control. According in other study has 20 cirrhotic they observed on WAIS performance tests. Cirrhotics performance were significantly worse than control $(7.9 \pm 2.0)$. This test alone was able to detect SHE in $11(55 \%)$ patients. Total performance IQ which was obtained from scaled score of subjects was significantly lower than in control. It identified SHE in 10 patients taken together in their study performance test was abnormal is $14(70 \%)$ patients [8].

In our study we also observed that on WAPIS test cirrhotics performed significantly worse than controls. Taken together the performance test was abnormal in 14 (56\%) cases. Performance of 3 cases was dull normal, 8 cases borderline according to IQ range 14 patients performed as mental defectives the incidence of SHE in our patients was less $(56 \%)$ than study done [8]. In contrast to same study symbol test and picture completion test are highly effective $(\mathrm{p}<0.0001)$ in diagnosing SHE while in picture arrangement test and object assembly test scaled score of case and control was not differed significantly ( $p>0.005)$. 


\section{Original Research Article}

Battery of Psychologic, Psychometric examination may take as long as two and half hours for WAPIS test and as little as $5 \mathrm{~min}$ for NCT, EEG taken about half an hour [7]. Blood specimen can be drawn rapidly, but the time for analysis may vary. Authors have mentioned that average time required to complete their test battery was $2.5 \mathrm{hrs}$ [17]. In our study the whole WAPIS test protocol required 120-150 min. \& NCT 10-20 min.

\section{Conclusion}

All psychometric tests require a competent examiner, organized material, a suitable room, adequate time and subject's co-operation. The examiner must be specially trained in individual testing. All tests need standardization for particular populations where it is to be used. SHE has impact upon cerebral function, leading to impairment in fitness for various tasks and professional capacity.

All these defects due to cerebral function impairment could be demonstrated by using psychometric test used in our study, most sensitive of them being WAPIS \& TMT. Such Groups of patients are prime candidates for "Prophylactic therapy"[18].

We concluded that for quick assessment of mental status and screening for detecting SHE in cases of cirrhosis of liver with portal hypertension, TMT test is useful and for complete assessment of cerebral function derangement WAPIS is most sensitive and complete test.

\section{Funding: Nil, Conflict of interest: None Permission of IRB: Yes}

\section{References}

1. Zeegen R, Drinkwater JE, Dawson AM. Method for measuring cerebral dysfunction in patients with liver disease. Br Med J. 1970 Jun 13;2(5710):633-6.

2. Conn HO. Trailmaking and number-connection tests in the assessment of mental state in portal systemic encephalopathy. Am J Dig Dis. 1977 Jun;22(6):541-50.

3. Conn. H.O. The hepatic encephalopathy. In conn H.O.., Bircher J., eds, Hepatic Encephalopathy Syndromes and therapies Bloomington, lllionis Med Ed Press, 1994; 1-12.

4. Conn H.O. Lieberthal M.M.: Pathogenesis of portal systemic encephalopathy. In the hepatic Coma syndromes and Lactulose. Baltimore Williams \& Wikins, 1978; 46-48.
5. R.M. Reiten, Validity of trail making test as an indicator of organic brain damage. Percept Mot Skills 8 1958; PP-271-276.

6. Bargara L., Sama C., Malavolti M. : The importance of recording in sub clinical hepatic encephalopathy, In: Therapy in liver Disease, J Rodes, V Arroyo eds. Barcelona: Ediciones Doyma, 1991;133-335.

7. Gitlin N, Lewis DC, Hinkley L. The diagnosis and prevalence of subclinical hepatic encephalopathy in apparently healthy, ambulant, non-shunted patients with cirrhosis. J Hepatol. 1986;3(1):75-82.

8. Sood G.K, Sarin S.K Mahapta J et al. comparative efficacy of psychometric test in detection of subclinical hepatic encephalopathy in nonalcoholic cirrhotics : search for a rational approach. Am $\mathrm{J}$ gastroenterol 1989; 84:156-159.

9. Rikkers L, Jenko P, Rudman D, Freides D: Subclinical Hepatic encephalopathy detection, Prevalence and Relationship to Nitrogen Metabolism. Gastroenterology 1978; 75:462-9.

10. Davidson E.A. Summerskill W.H.J. psychiatric aspects of liver disease. Postgrad Med J 1956; 32: 487-494.

11. Levy LJ, Leek J, Losowsky MS. Evidence for gamma Aminobutyric Acid as the inhibitor of gamma Aminobutyric Acid binding in plasma of Humans with liver diseases and Hepatic encephalopathy. Clin Sci (Lond). 1987 Nov;73(5):531-4.

12. Gilberstadt S.J. Gilberstadt H., Zieve L., et al:. Psychomotor performance defect in cirrhotic patients without overt encephalopathy. Arch Intern Med 1980; 140: 519-521.

13. Groeneweg M, Moerland W, Quero JC, Hop WC, Krabbe PF, Schalm SW. Screening of subclinical hepatic encephalopathy. J Hepatol. 2000 May; 32 (5): 748-53.

14. Gitlin N, Lewis D.C. Hinkely L. The diagnosis and prevalence of subclinical hepatic encephalopathy in apparently health, ambulant, non-shunted patients with cirrhosis. J Heptol 1986;:3:75-82.

15. Sarin S.K. Nundy S. Sub normal encephalopathy after portosystemic shunts in patients with non-cirrhotic portal fibrosis. Liver. 1985 Jun; 5 (3):142-6. 


\section{Original Research Article}

16. Gilberstadt S.J. Gilberstadt H., Zieve L., et al. Psychomotor performance defect in cirrhotic patients without overt encephalopathy. Arch Intern Med. 1980 Apr; 140 (4):519-21.

17. Trate R.E. Hegedus A.M. Van Thiel D.H. et al.: Nonalcoholic cirrhosis associated with neuro phsychological dysfunction in the absence of overt evidence of hepatic encephalopathy. Gastroenterology 1984; 86:1421-1427.

18. Szerb JC, Butter worth RF. Effect of Ammonium ions on synaptic transmission in mammalian central nervous system. Prog Neurobiol. 1992 Aug; 39 (2): 135-53.

\section{How to cite this article?}

Kanwar G., Singh S, Pandey S, Paikra S. The study of psychometric test for detection and assessment in subclinical hepatic encephalopathy. Int J Med Res Rev 2018;6(05):252-258. doi:10.17511/ijmrr. 2018.i05.03. 